\title{
Follicle Stimulating Hormone Deficiency
}

National Cancer Institute

\section{Source}

National Cancer Institute. Follicle Stimulating Hormone Deficiency. NCI Thesaurus. Code C121141.

Subnormal concentration of follicle stimulating hormone. 